\title{
Assessing the influence of primary soil particles on soil aggregate distribution for different breakdown mechanisms: A new method
}

\author{
Hai Xiao ${ }^{1}$, Mingyi Li $^{1}$, Yueshu Yang ${ }^{1}$, Feng Gao ${ }^{1}$, Zhenyao Xia ${ }^{1}$, Lun Zhang ${ }^{1}$, Ping Guo ${ }^{1}$, \\ and Wennian $\mathrm{Xu}^{1}$ \\ ${ }^{1}$ China Three Gorges University
}

July 14, 2020

\begin{abstract}
Soil aggregates are the basic unit structing soils, and their stability is an important index for soil degradation. However, current methodologies rarely assess the influence of primary soil particles on soil aggregates distribution for different breakdown mechanisms. Therefore, a new method that separates the primary soil particles from the soil aggregates for different breakdown mechanisms with a series of in-lab experiments were developed to fill this gap. The whole soil sample was treated by fast wetting, slow wetting, and mechanical breakdown by pre-wetting and stirring to simulate the different breakdown mechanisms of slaking, differential swelling of clays, and mechanical breakdown by raindrop impact, respectively. Then, attempts were made to separate the primary soil particles from the soil aggregates of various particle size fractions by using sodium hexametaphosphate and hydrogen peroxide to eliminate the influence of the primary soil particles on the soil aggregate distribution. Four soils collected from different areas with different soil textures were used to assess the soil aggregate distribution by using the new method to highlight the importance of separating the primary soil particles from the soil aggregate for different breakdown mechanisms. The results indicated that the primary soil particles have much greater influence on the micro-aggregates than on macroaggregates. Different breakdown mechanisms and soil types could affect the influence of the primary soil particles affects the on soil aggregate distribution. This study highlights the influence of separate primary soil particles on soil aggregate distribution for different breakdown mechanisms.
\end{abstract}

\section{Hosted file}

Manuscript0713.doc available at https://authorea.com/users/340147/articles/469593-assessingthe-influence-of-primary-soil-particles-on-soil-aggregate-distribution-for-differentbreakdown-mechanisms-a-new-method 


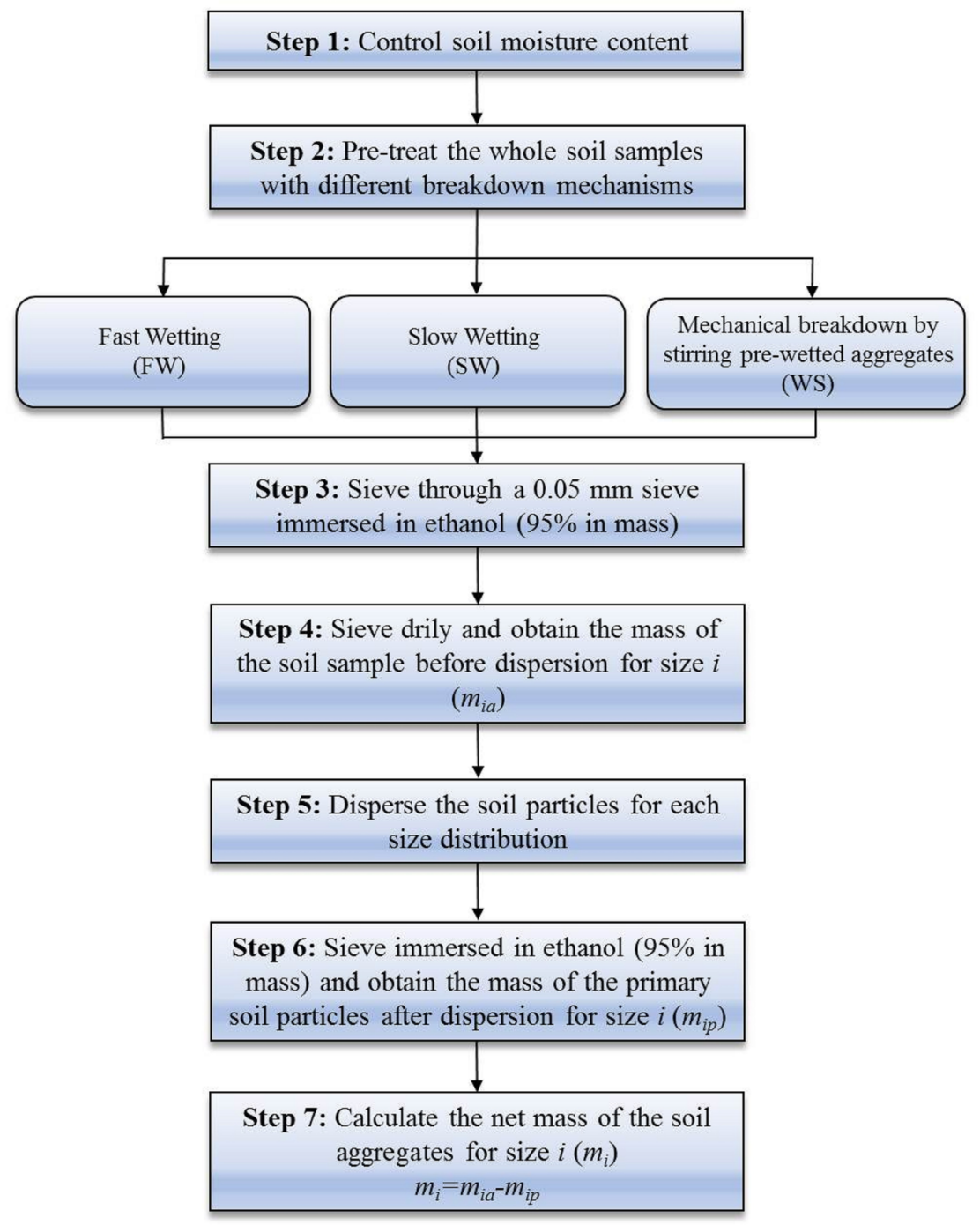



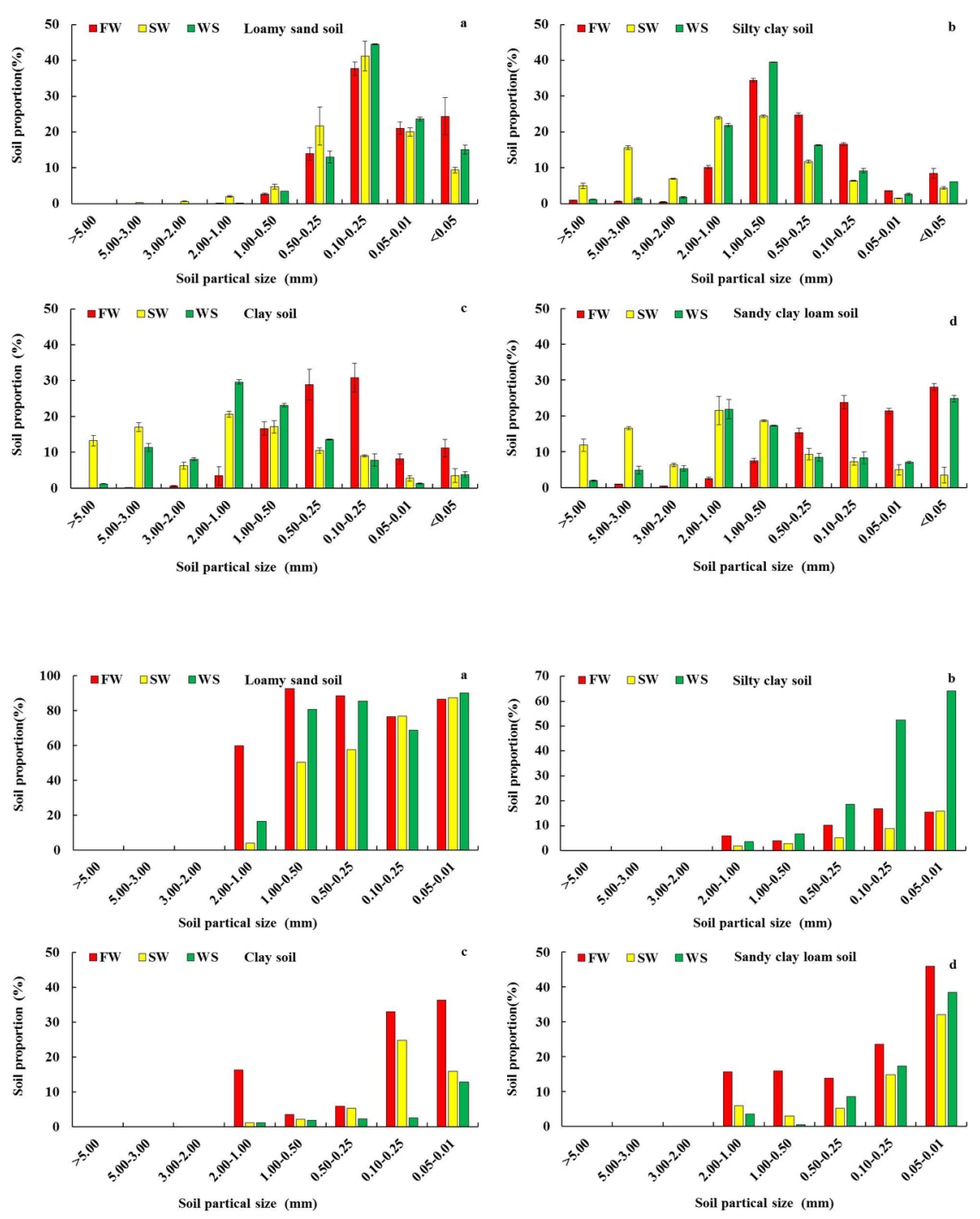